\title{
\#Fermilab
}

Managed by Fermi Research Alliance, LLC for the U.S. Department of Energy Office of Science

\section{High Intensity Proton Stacking at Fermilab: 700 kW Running}

\author{
Rob Ainsworth
}

HB2018

19th June 2018 


\section{Outline}

- Accelerator complex

- Repurposed Recycler

- Power evolution

- Slip-stacking

- Running in 2016 and issues

- Changes and Running in 2018

- Summary and future plans 


\section{Accelerator complex}

- $\mathrm{H}^{-}$linac

- Booster

- $h=84$

- $15 \mathrm{~Hz}$

- $400 \mathrm{MeV}->8 \mathrm{GeV}$

- Recycler

- $\mathrm{h}=588$

- Slip-stack 12 batches (double bunch intensity)

- Main Injector

- $8 \mathrm{GeV}$-> $120 \mathrm{GeV}$

\section{Fermilab Accelerator Complex}

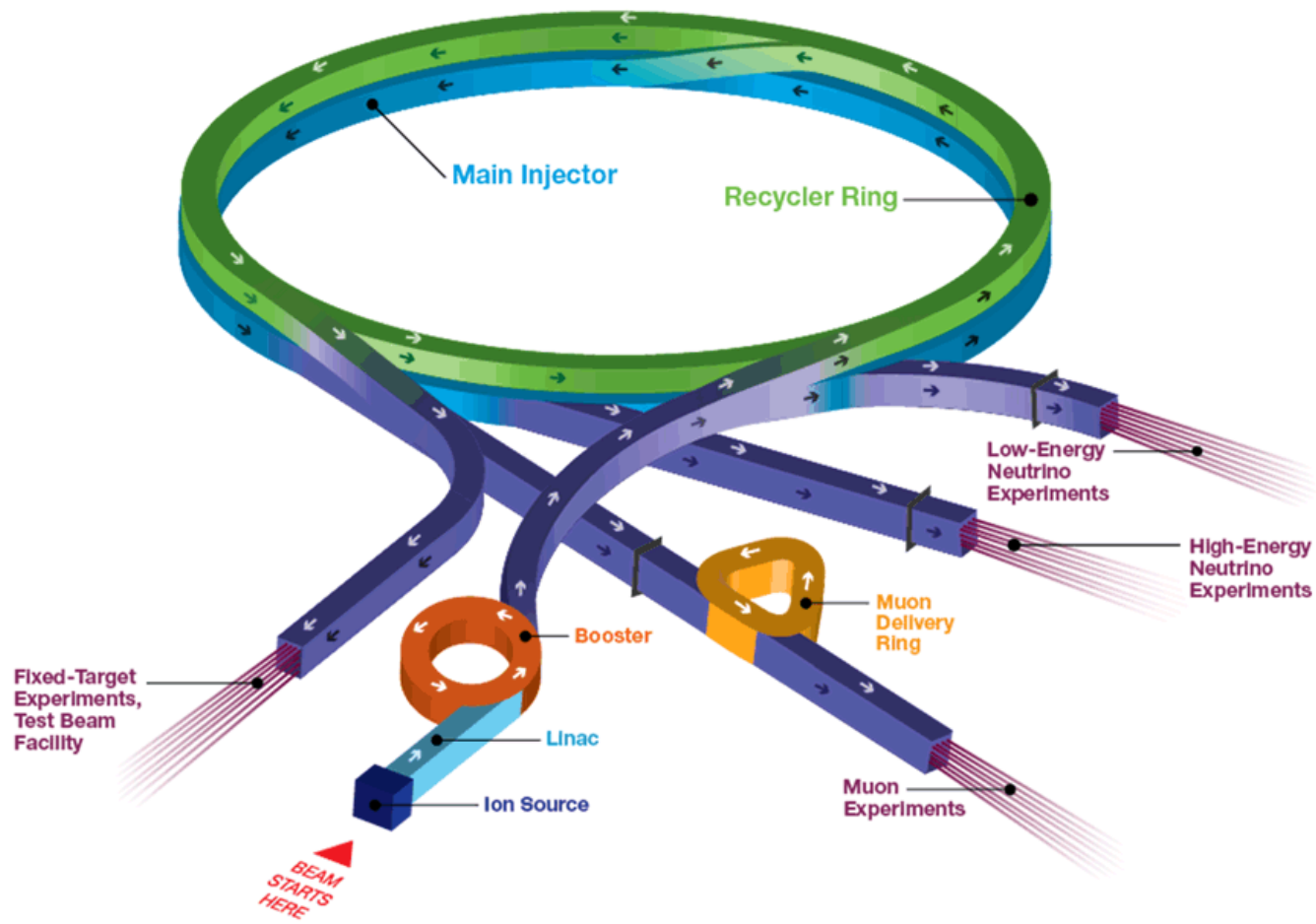




\section{Repurposed Recycler}

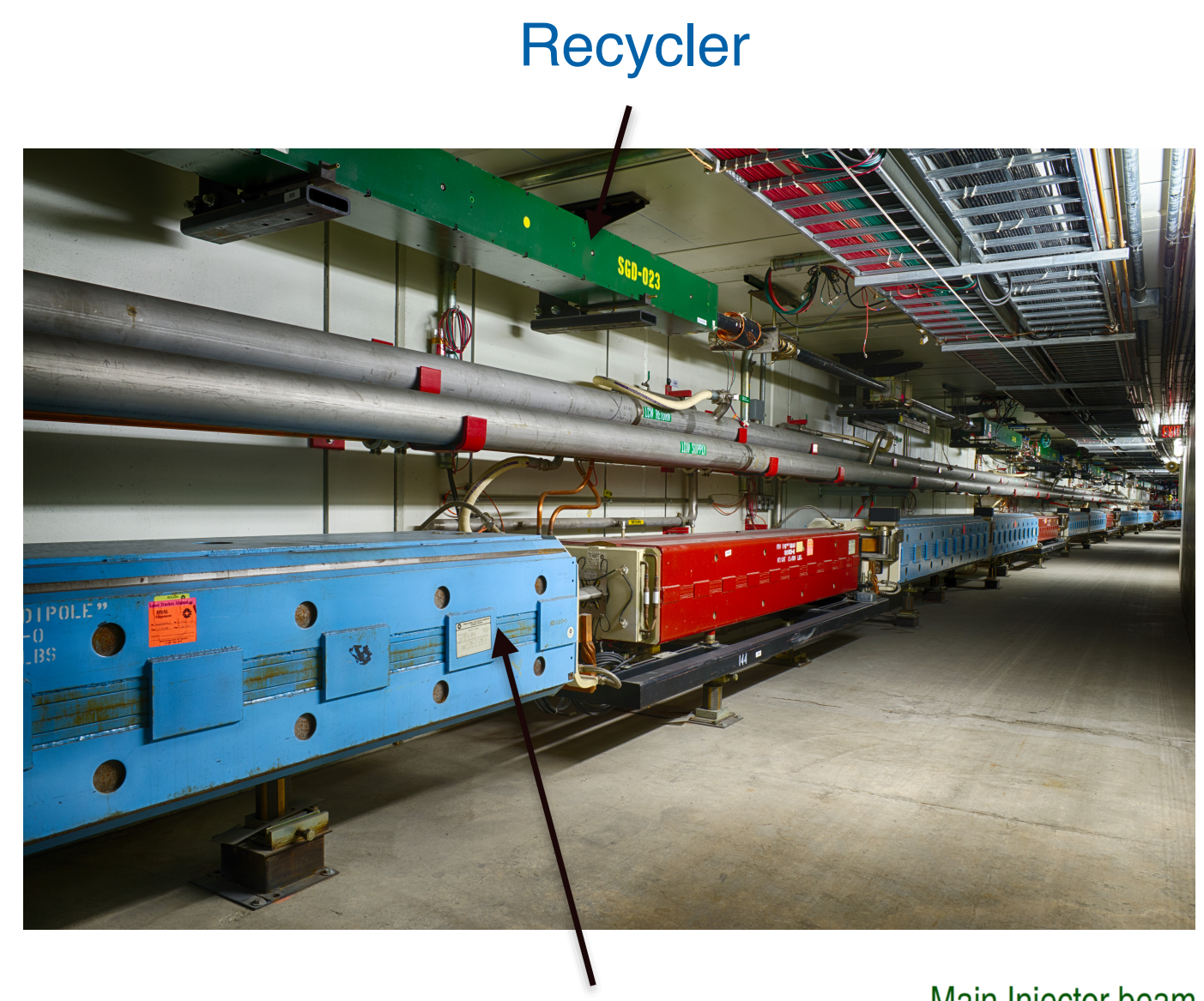

Main Injector beam pipe

Main Injector
- Recycler is a permanent magnet storage ring

- Shares the tunnel with the Main Injector

- Originally named to recycle pbars from Tevatron which it never did!

- Eventually it stored and cooled pbars

- Contributed greatly towards increased Tevatron luminosity

Never designed for its current purpose 


\section{Scheme to increase beam power}

- Slip-stack in the Recycler

- Increase the MI ramp rate $(204 \mathrm{GeV} / \mathrm{s}$ to 240 $\mathrm{GeV} / \mathrm{s})$

-2.2->1.33 s cycle time

- Achieve $700 \mathrm{~kW}$ with just a 10\% increase in beam intensity from MI only
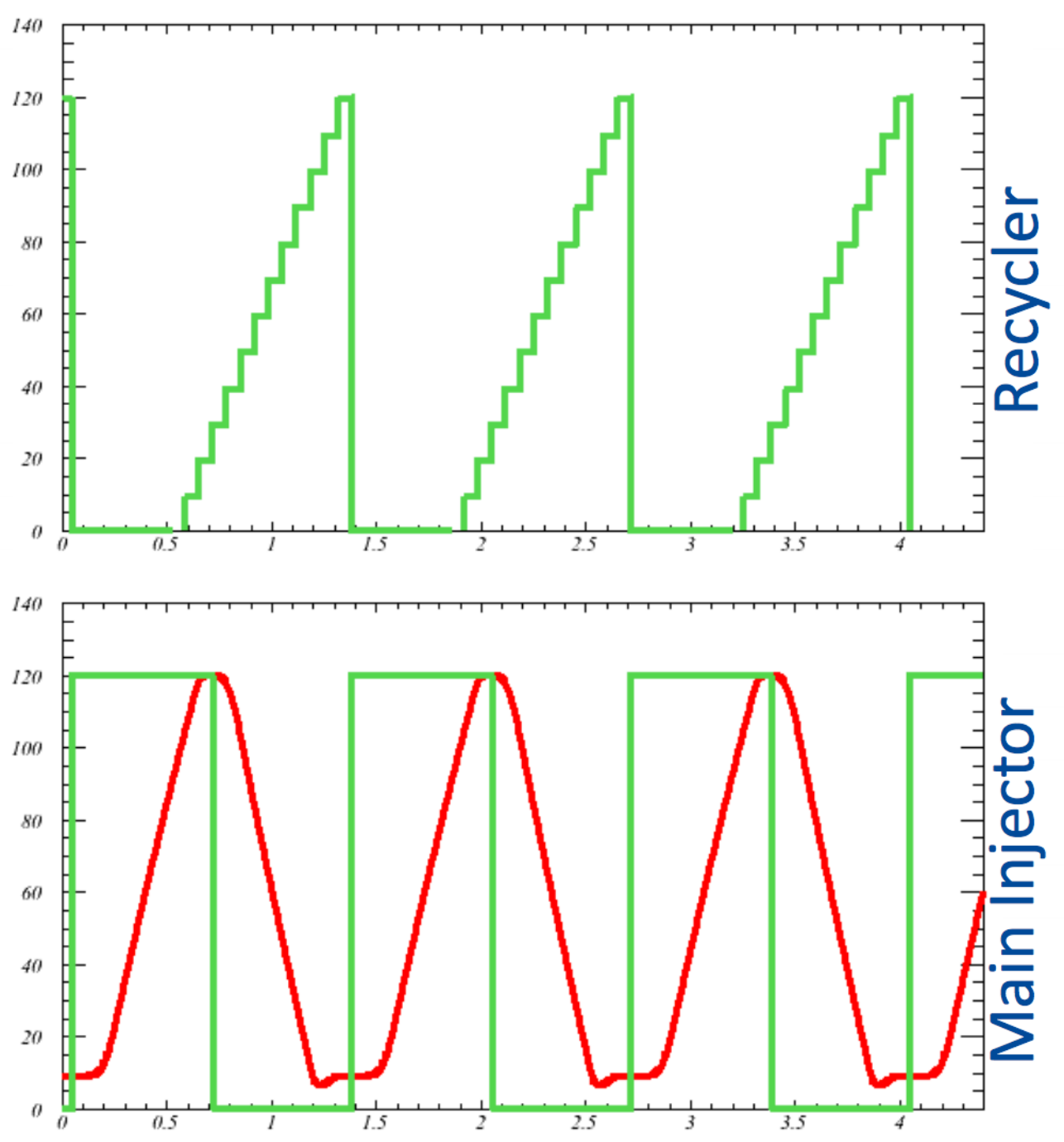

苚 Fermilab 


\section{Power}

\section{Running 700 kW consistently since Jan 2017}

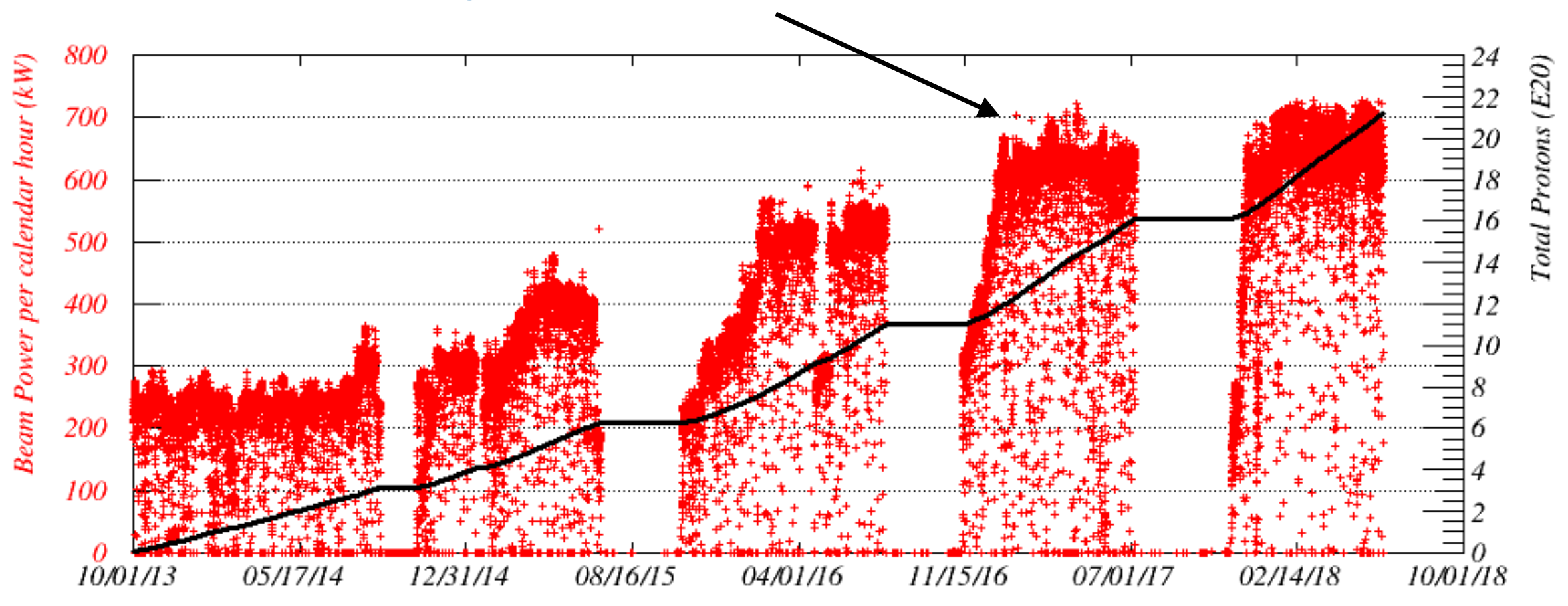

\begin{tabular}{|c|c|c|c|c|}
\hline MI & $\mathrm{RR}$ & $2+6$ & $4+6$ & $6+6$ \\
$240 \mathrm{~kW}$ & $300 \mathrm{~kW}$ & $400 \mathrm{~kW}$ & $525 \mathrm{~kW}$ & $700 \mathrm{~kW}$ \\
\hline
\end{tabular}




\section{Slip stacking}

- Slip-stacking allows us to double the intensity of the bunches in the Recycler

$\Delta f=h_{b} f_{b}$

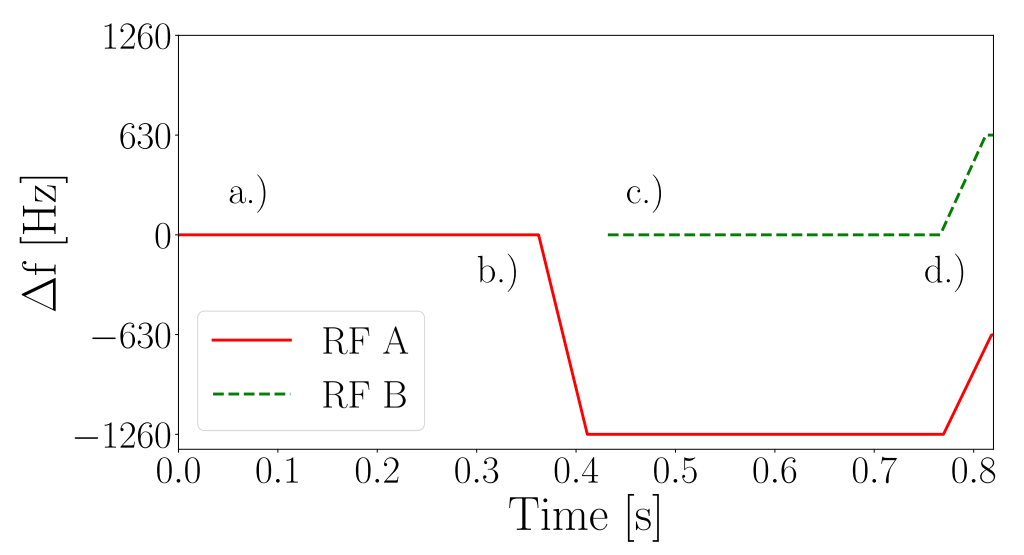

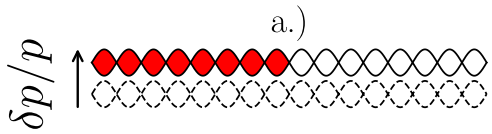

Inject bunches into RR on-momentum

b.)

$\infty \infty \times \infty \times \infty \times \infty$

Decelerate bunches by $1260 \mathrm{~Hz}$

c.)

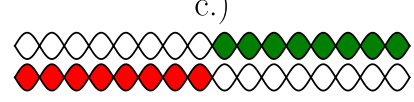

d.) 10000000000000 $\infty \times 10000000$

Position
Turn on second RF cavity and inject more bunches on-momentum Decelerated batches will slip. Once fully overlapped, all bunches are extracted. 


\section{Beam in the gap \& un-captured beam}

Simulation

$40 \mathrm{MeV}$
$-40 \mathrm{MeV}$
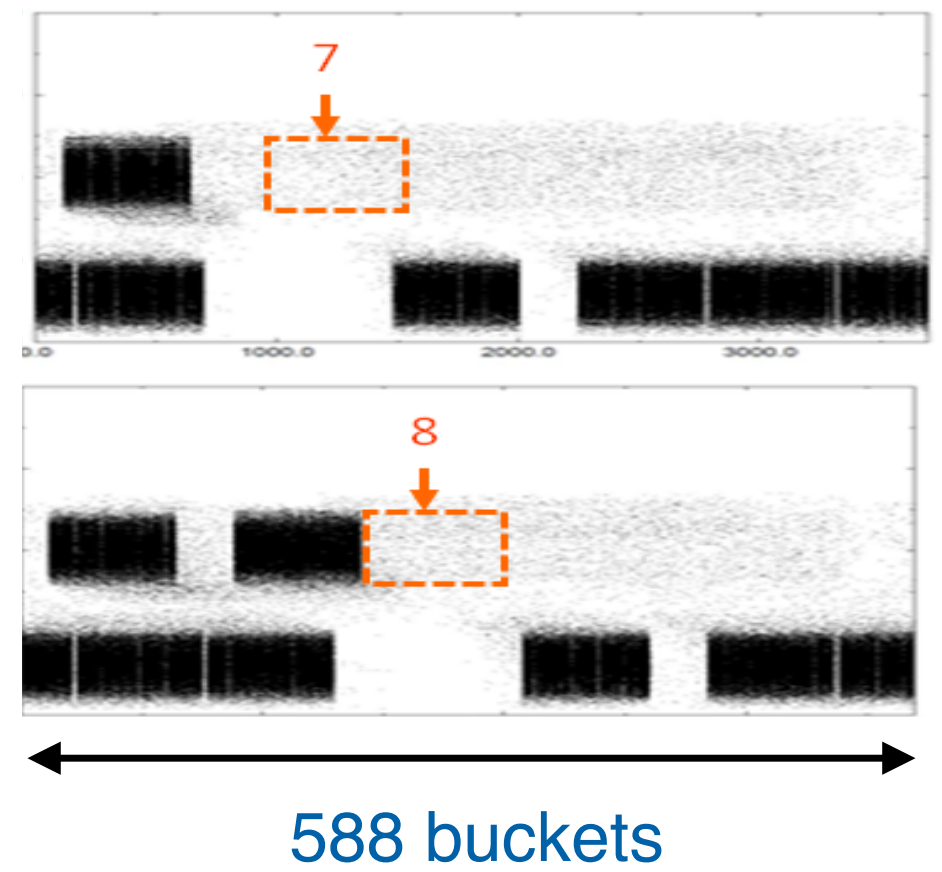
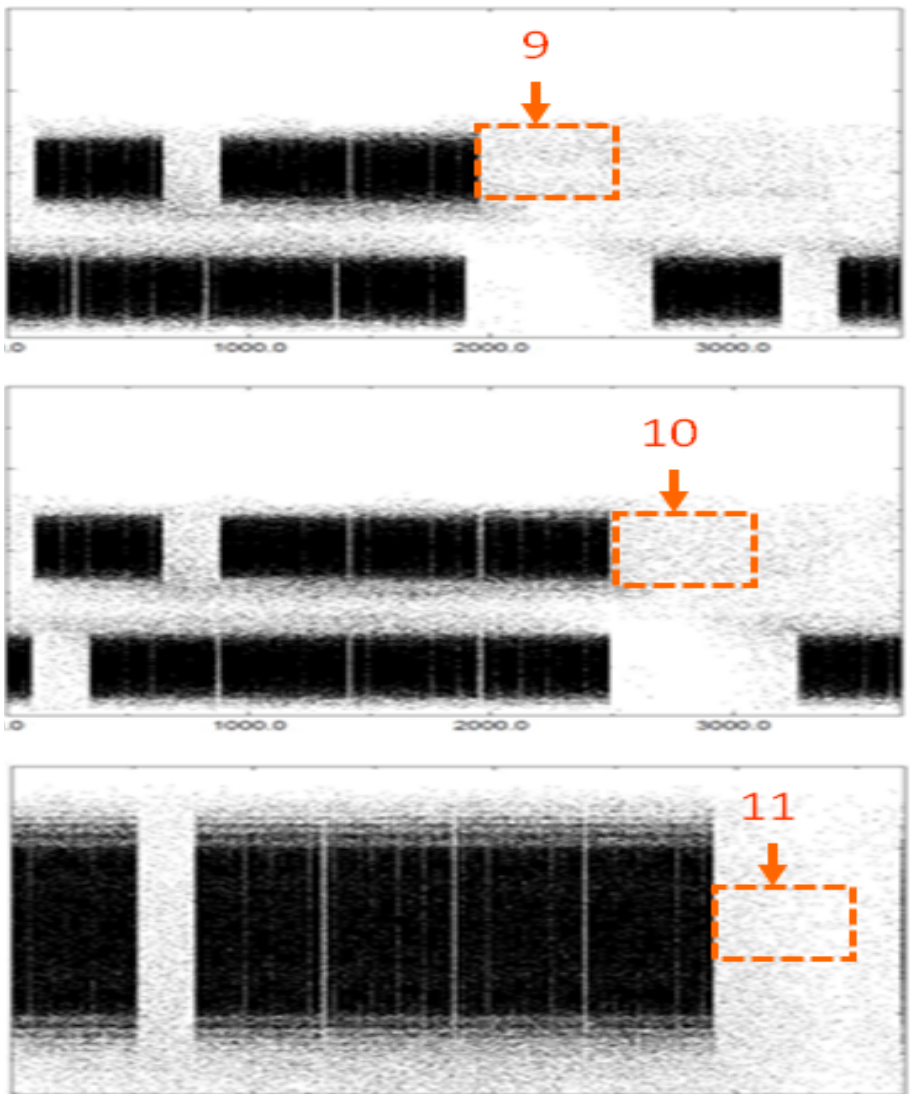

Gap clearing kickers fire before every injection sending beam to abort 范 Fermilab 


\section{Typical 6+6 cycle -2016}

- 6 batches injected and then decelerated

- Further 6 injected

- Bunch by bunch damper systems turn off (cannot deal with slipping)

- Chromaticity raised to control resistive wall instability

42E12 ppp
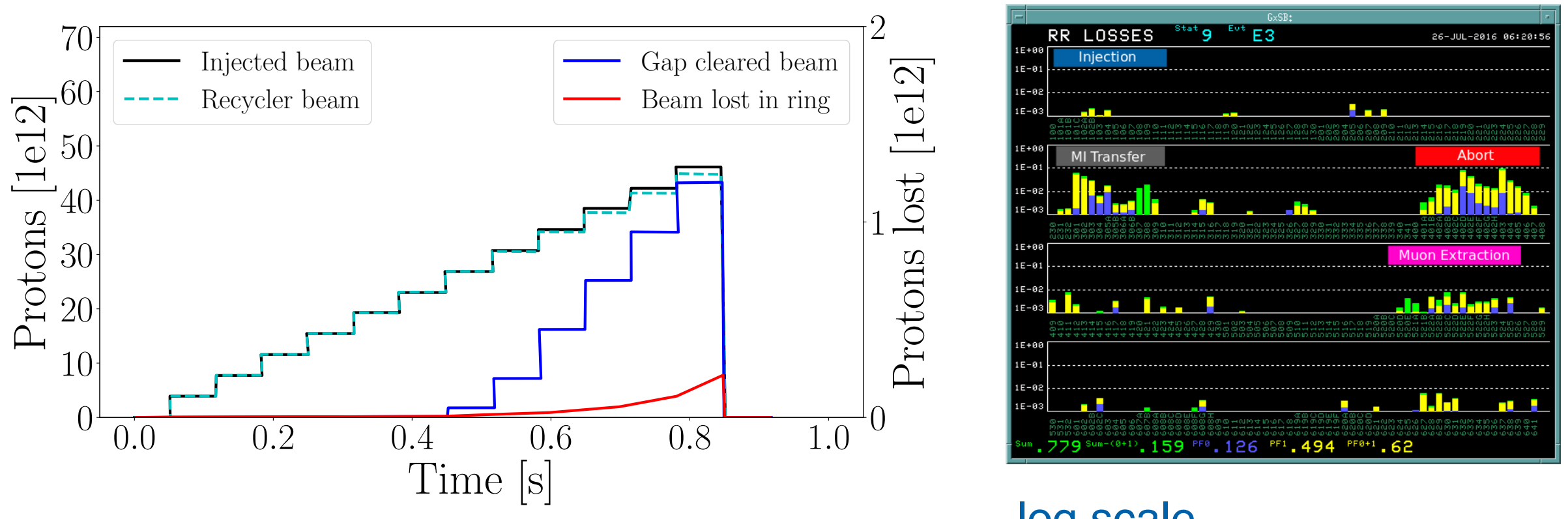

$\log$ scale 


\section{High Chromaticity running}

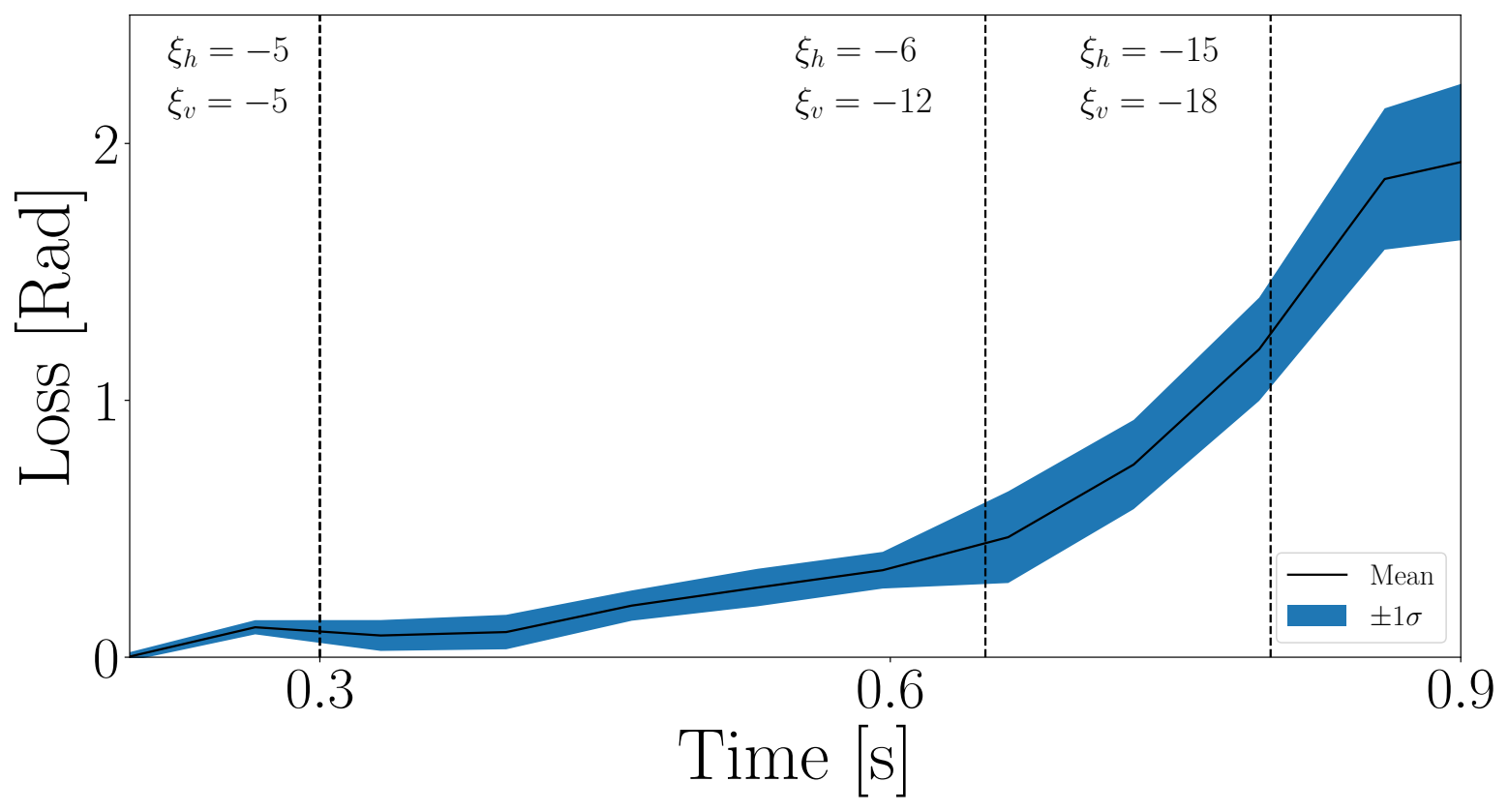

Exponential increase in losses as chromaticity increases

High chromaticity constrains tune space due to off-momentum beam

$$
\begin{aligned}
& \triangle Q=\xi \delta p / p \\
& \text { at }-5, \text { tune shift } \sim 0.013 \\
& \text { at }-20, \text { tune shift } \sim 0.048
\end{aligned}
$$

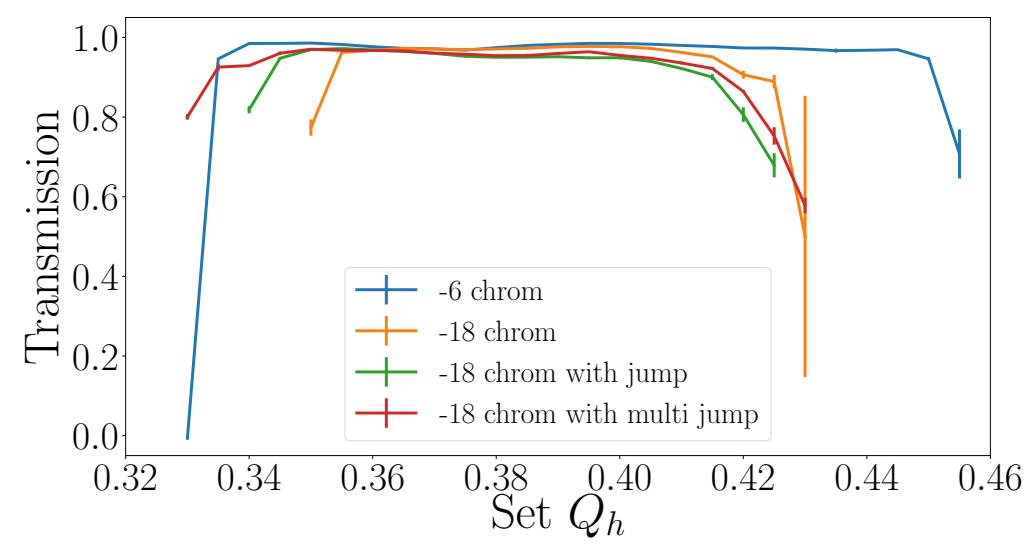




\section{Injection phase offsets (Longitudinal Emittance dilution)}
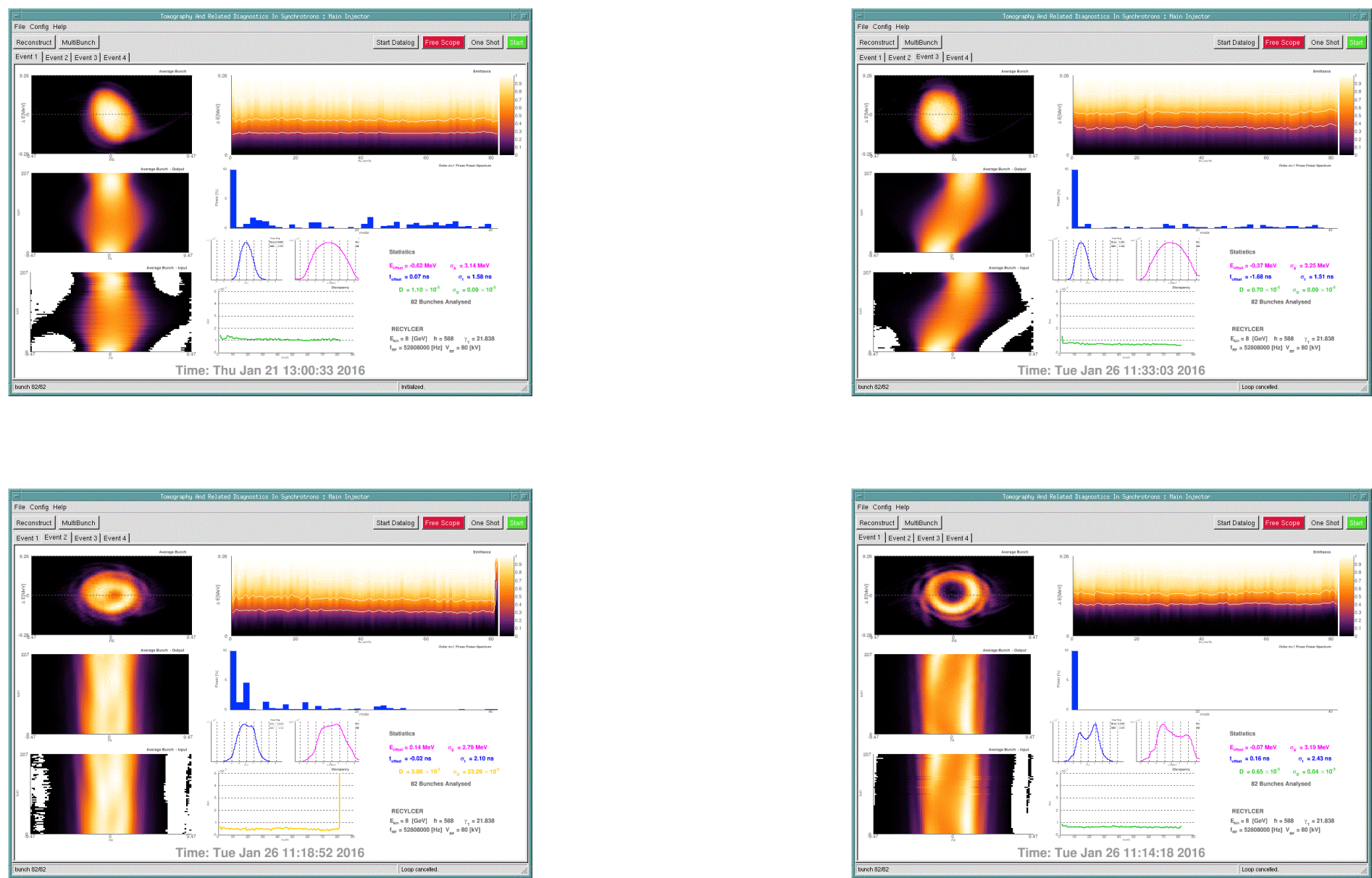

-allowed the final chromaticity to be reduced by 2-3 units

- resulted in more beam sent to abort (controlled) 


\section{Issues - 2016 shutdown}

- Transverse losses are not controlled!

- No damper during slipping

- Need high chromaticity for stability 


\section{Collimators}

\section{2 stage system}

- primary scraping foil edge (vertical)

- two 20 ton secondaries

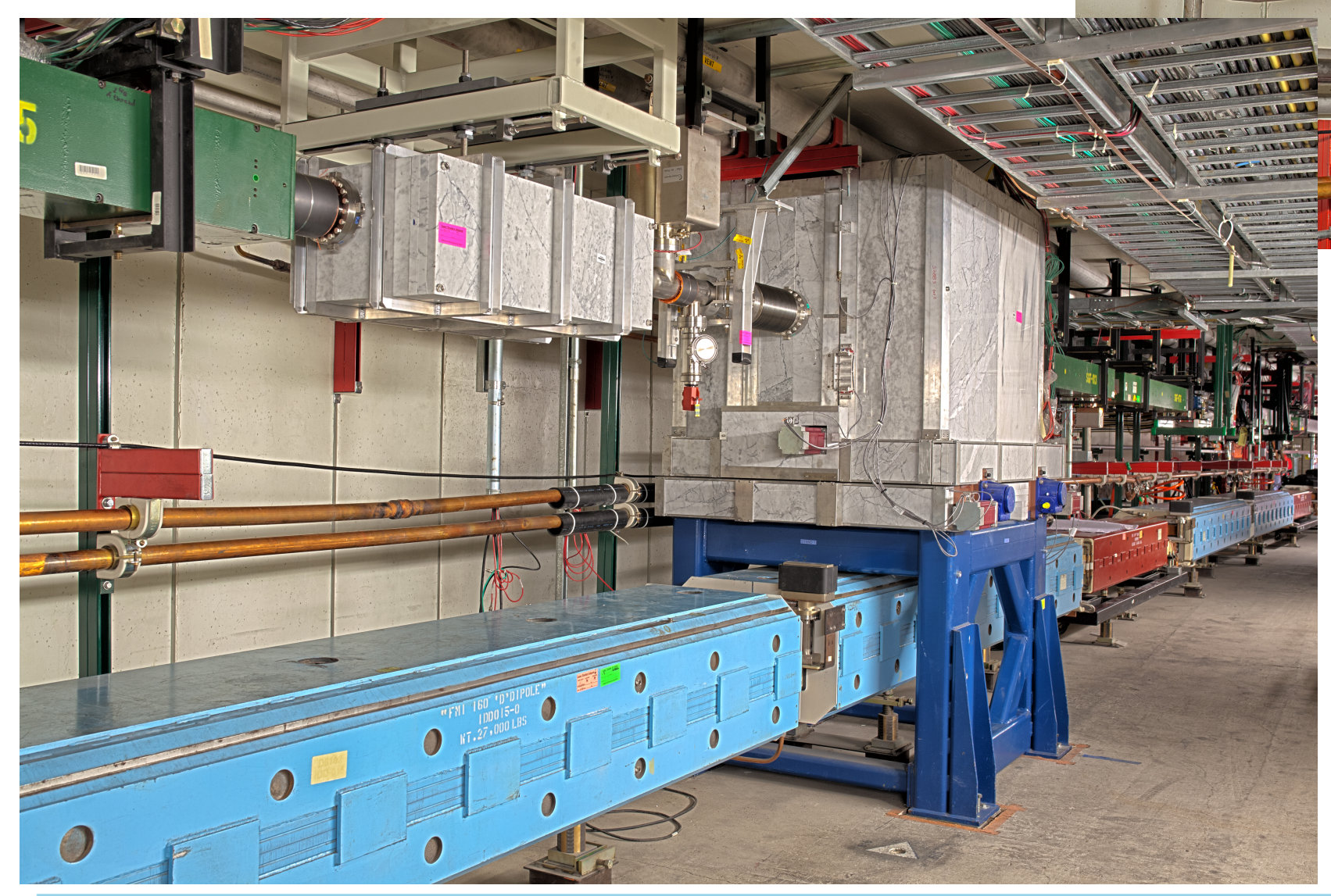




\section{Collimation}

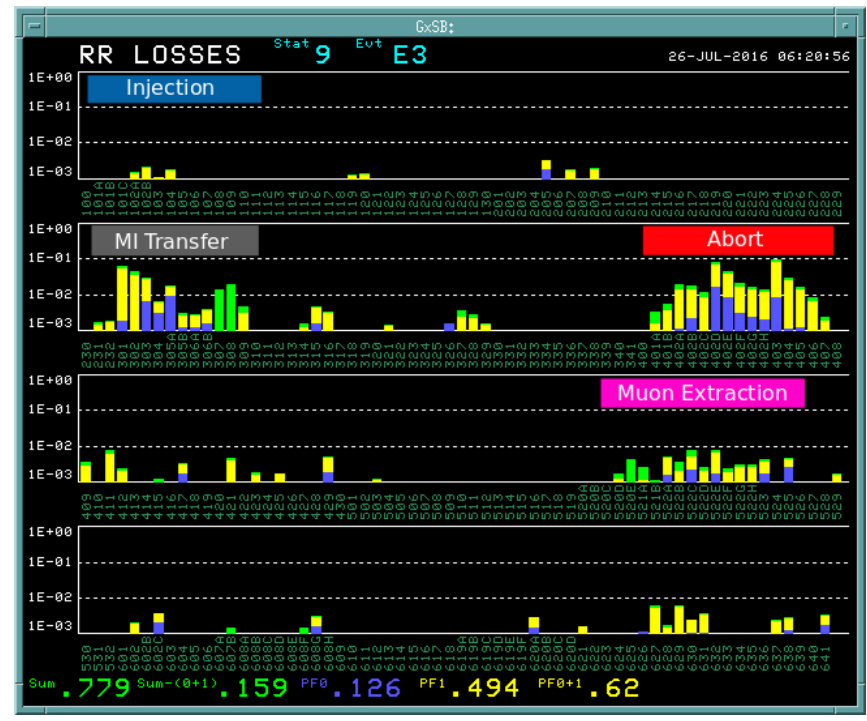

42E12 ppp

Big improvement at MI Transfer Lambertson

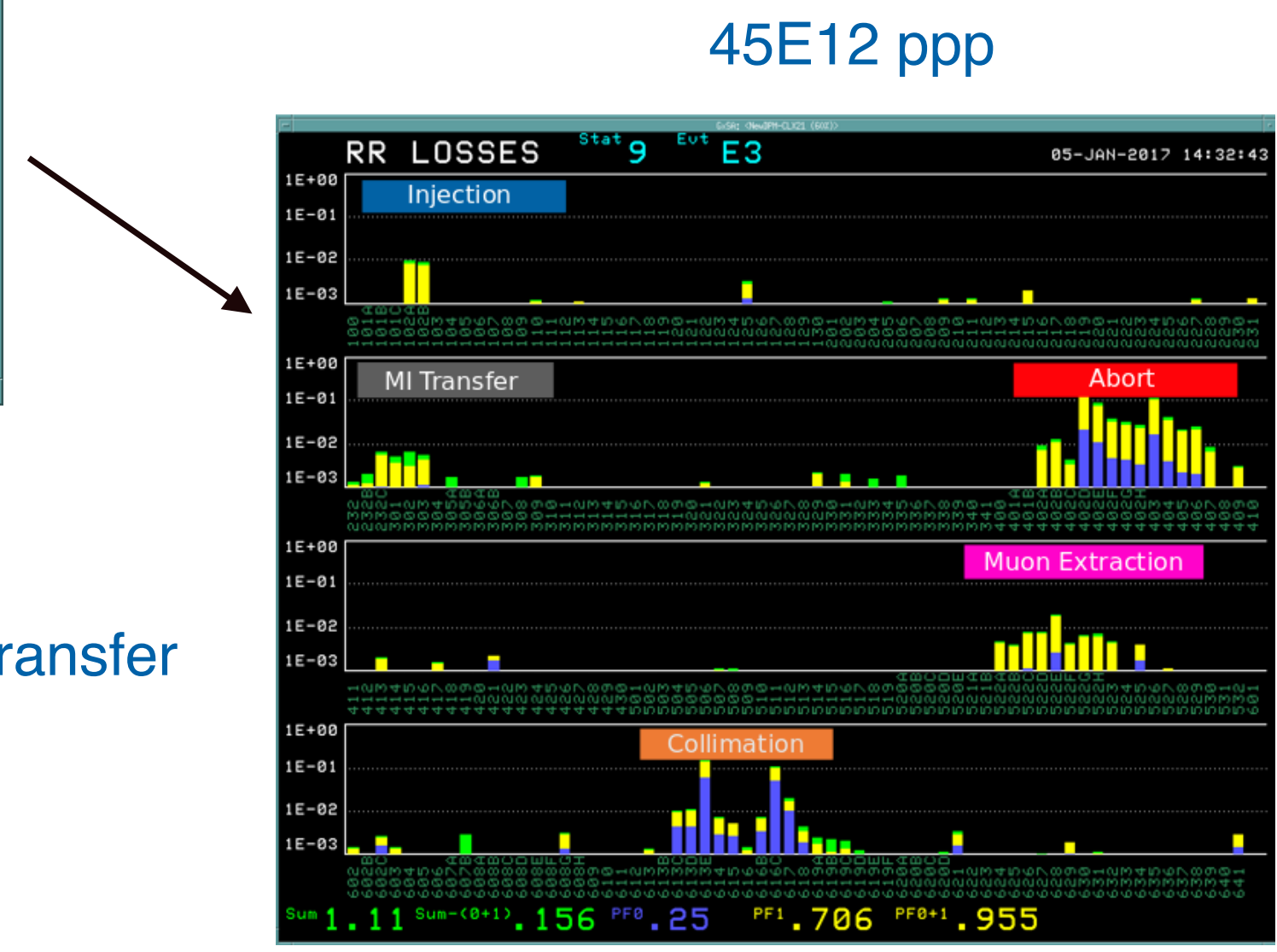




\section{Slip stack damper}

- It was proposed that the bunches in the two beams perform the same motion

- A lower bandwidth damper looking at the envelope could be sufficient

- Damper system developed based on Direct Diode Detection (3D) concept

- System implemented in Jan 2017. The new damper system turns on during the cycle as the bunch by bunch dampers turn off. 


\section{Diode damper}

Diode damper allowed final chromaticity to be reduced from -20 to -7

\section{E12 ppp}

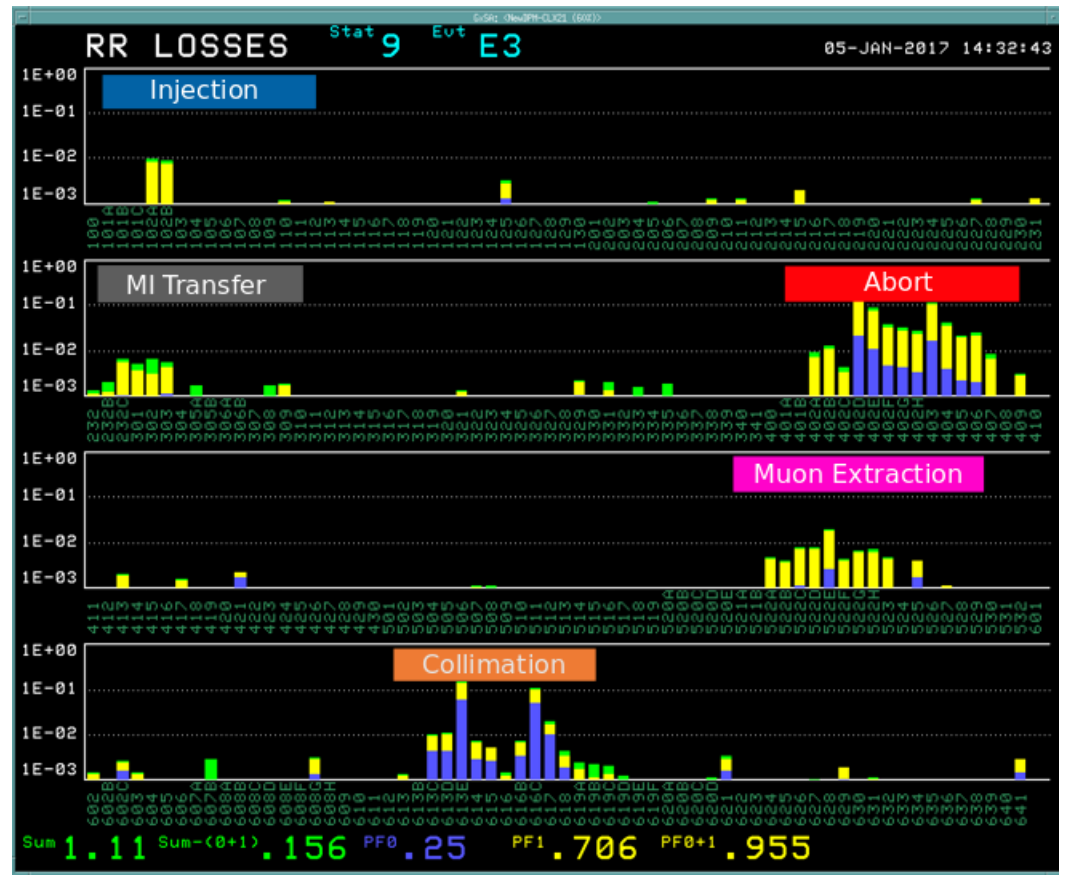

\section{E12 ppp}

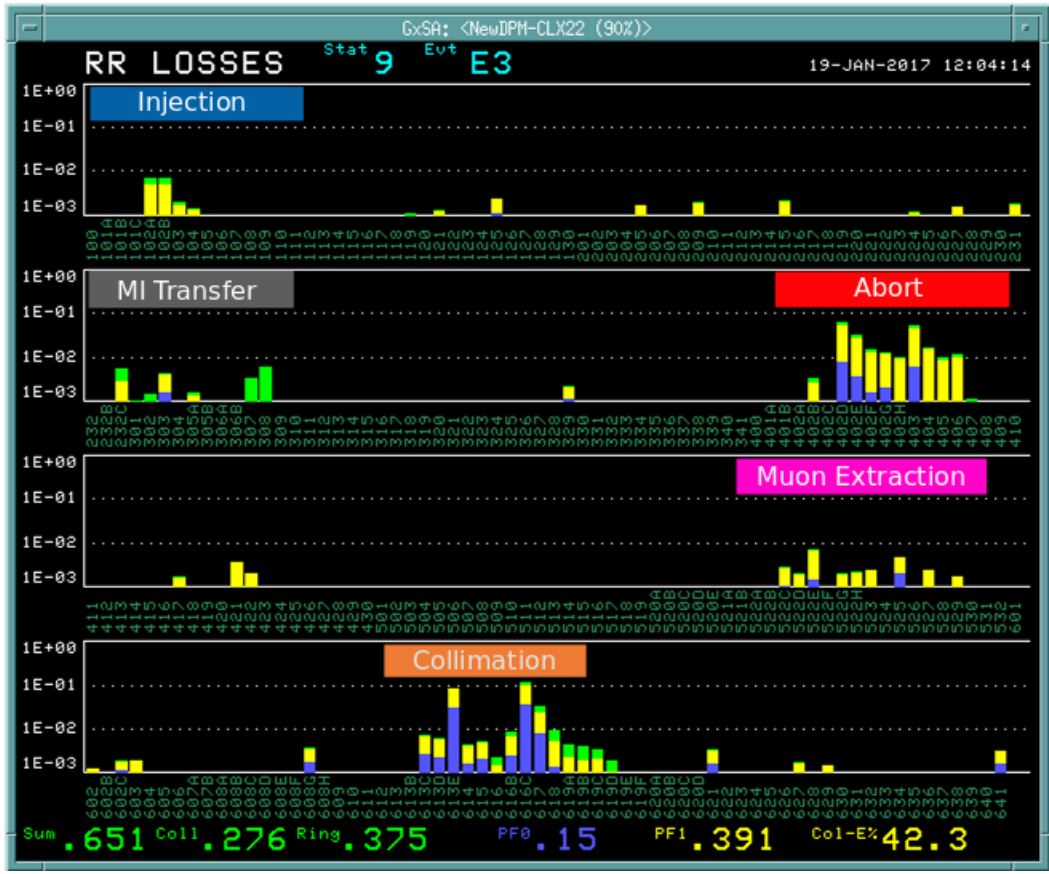




\section{Aperture improvements}

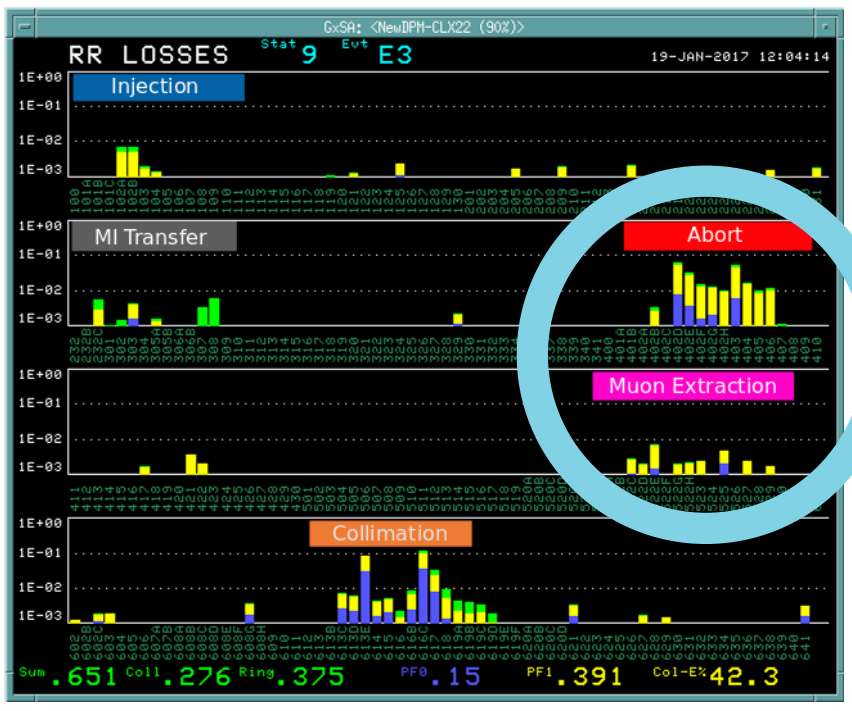

45E12 ppp
Old

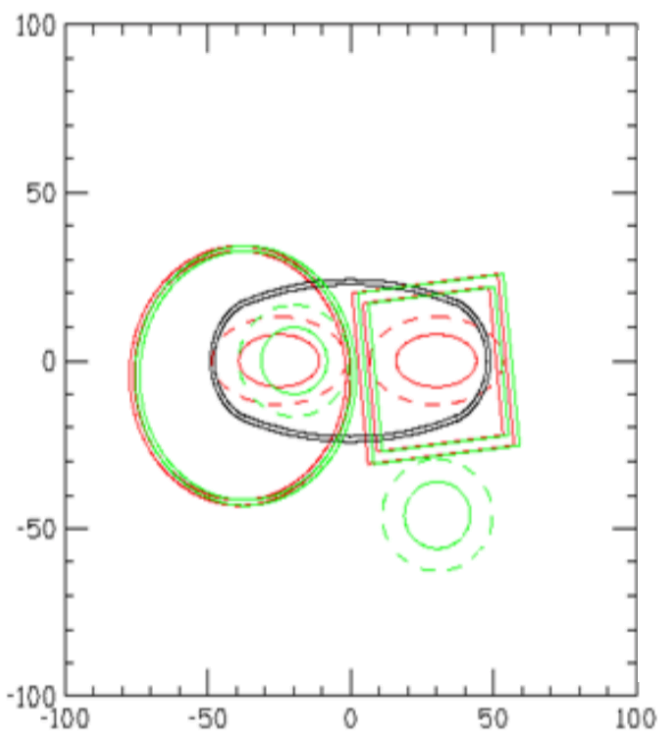

New

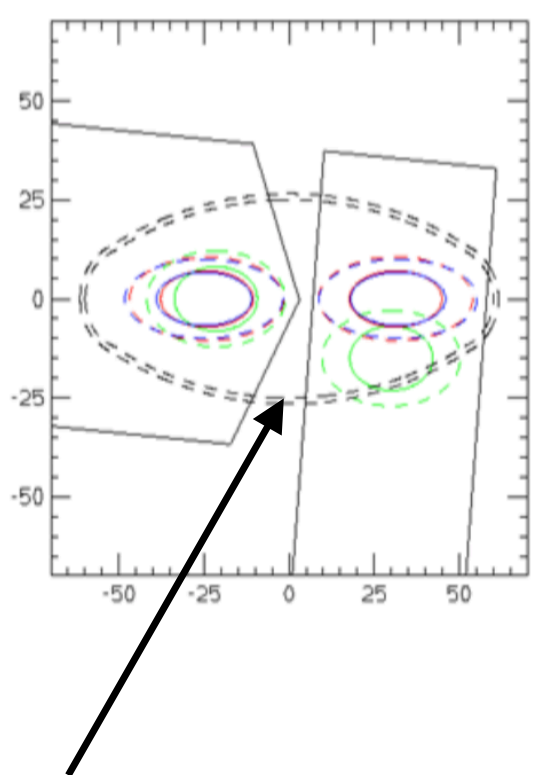

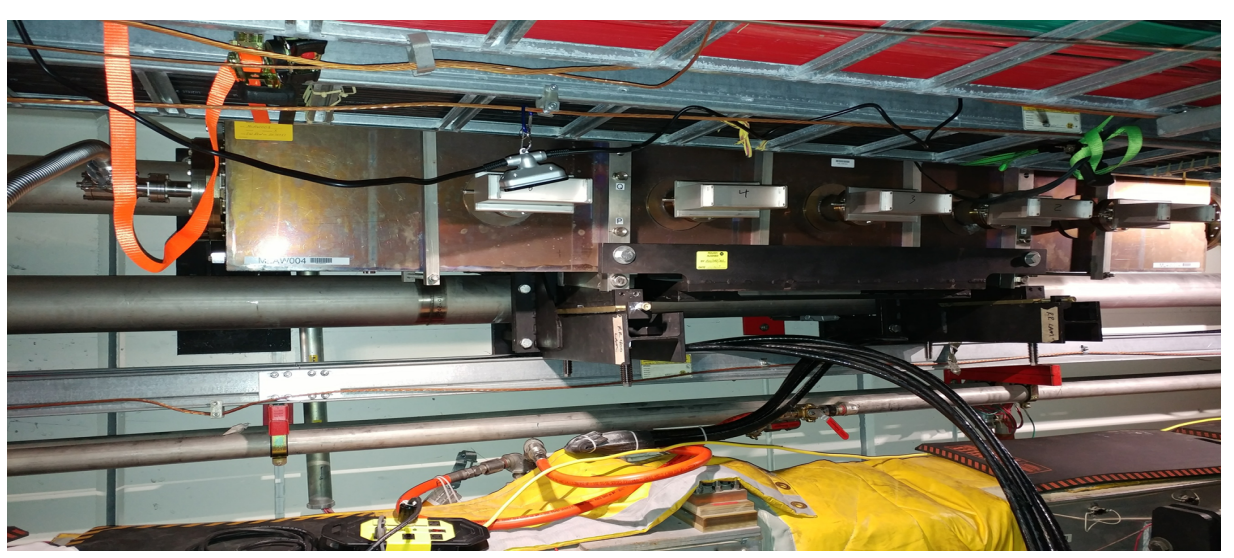




\section{Typical 6+6 cycle - 2018}

- Gap cleared beam reduced by a factor $\sim 3$

- large portion of ring losses go to collimators

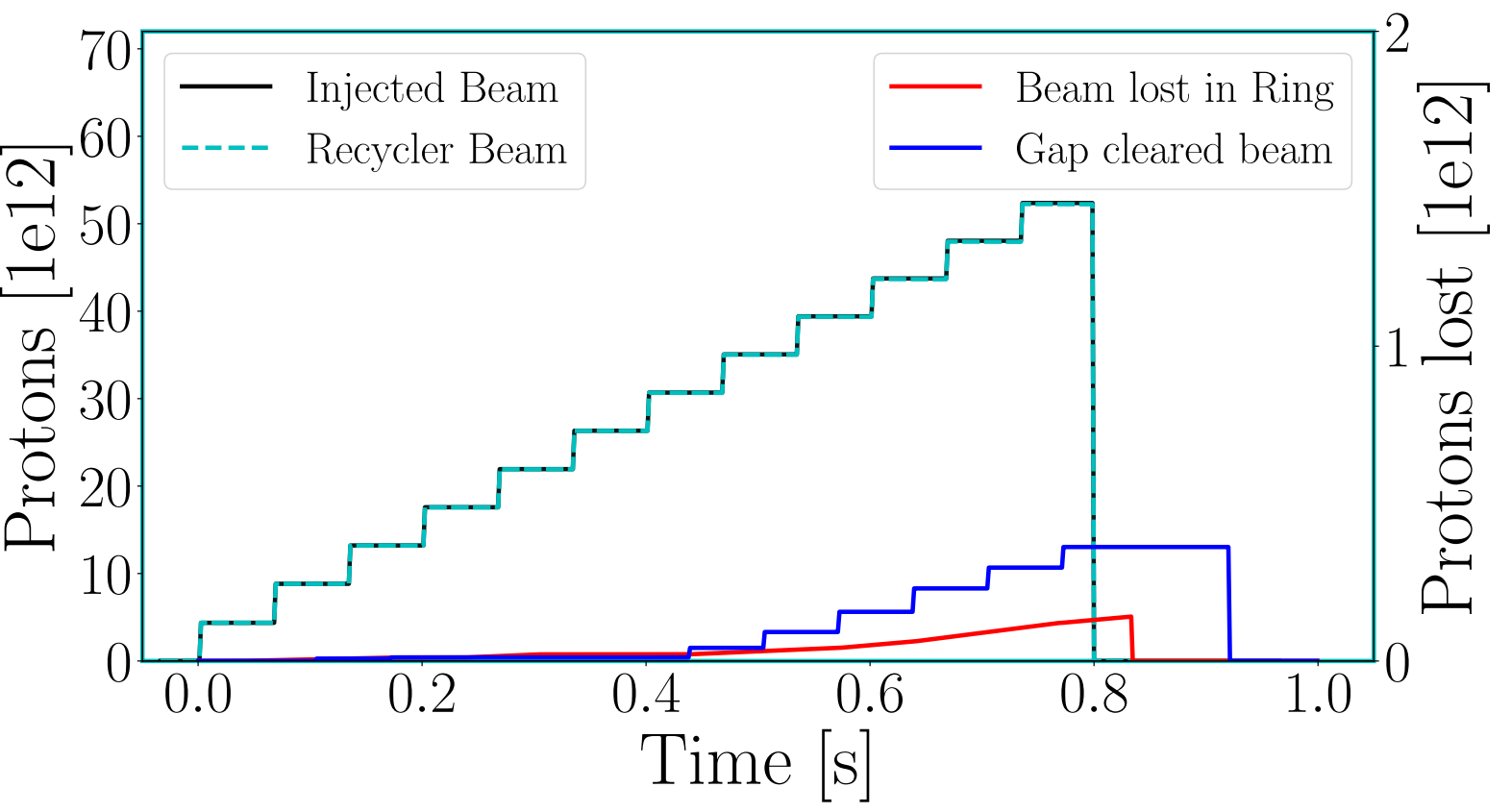

50E12 ppp

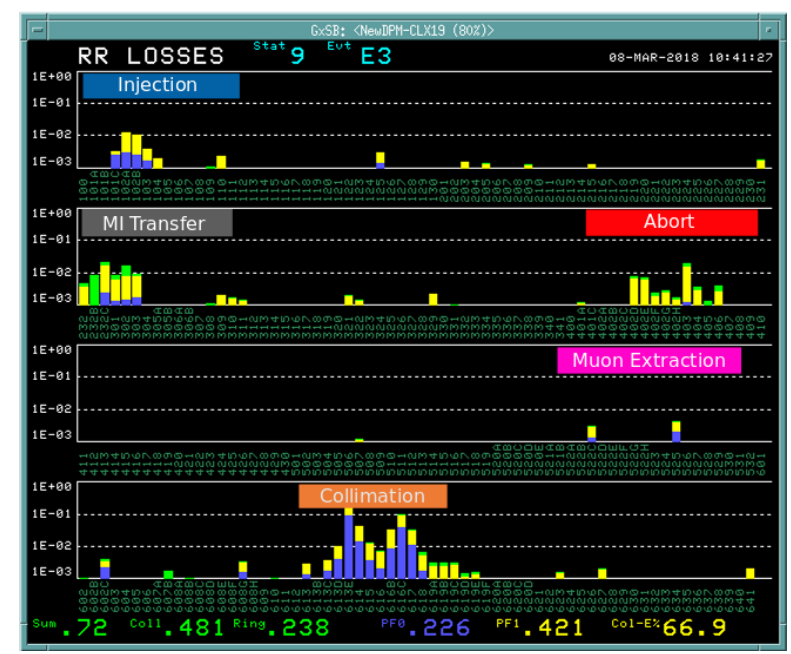




\section{Instabilties}

- Previously, a fast instability attributed to electron trapping in the gradient magnets was observed but was avoided by rotating the bunches

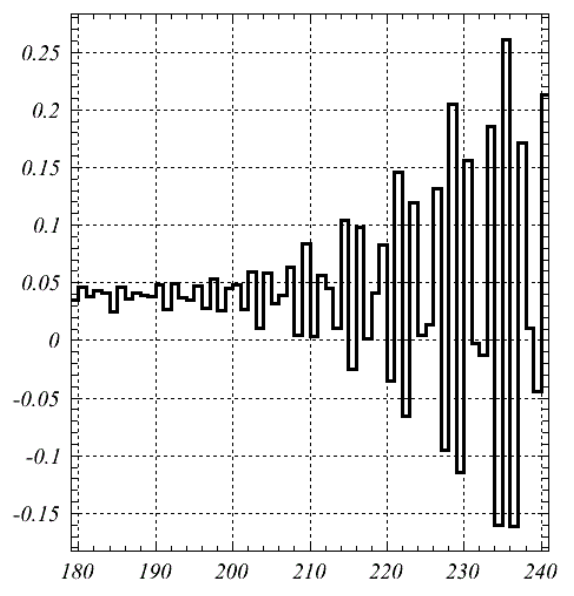

Observed on BPMs, growth rate 10-15turns

- Fast instability was not observed during commissioning this year

- Conditioned vacuum pipe

- Vacuum changes, TSPs -> Ion Pumps may have affected things too

- Tried to induce instability in RR with high intensity bunches ( 6e10, -3,-3 chromaticity, short bunches) but observed nothing 


\section{Radiation Survey around Ring}

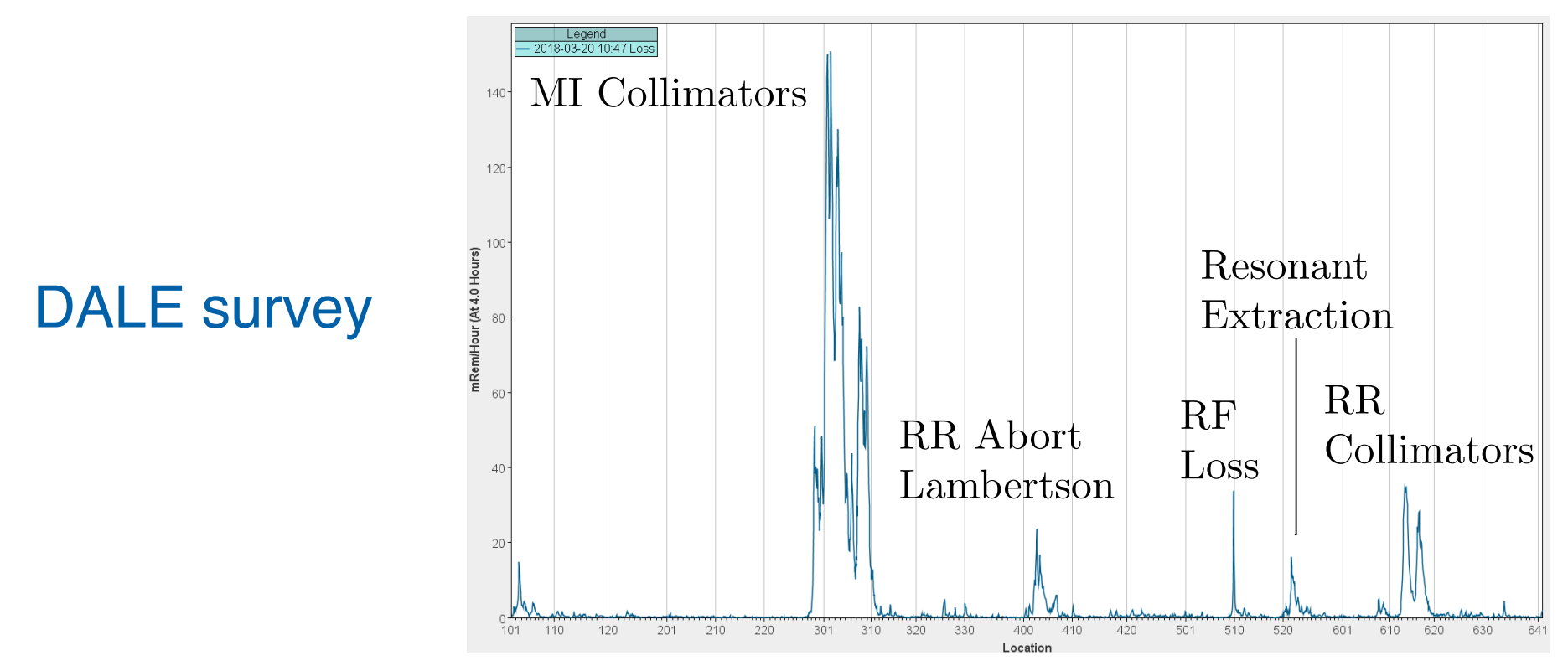

Loss monitors

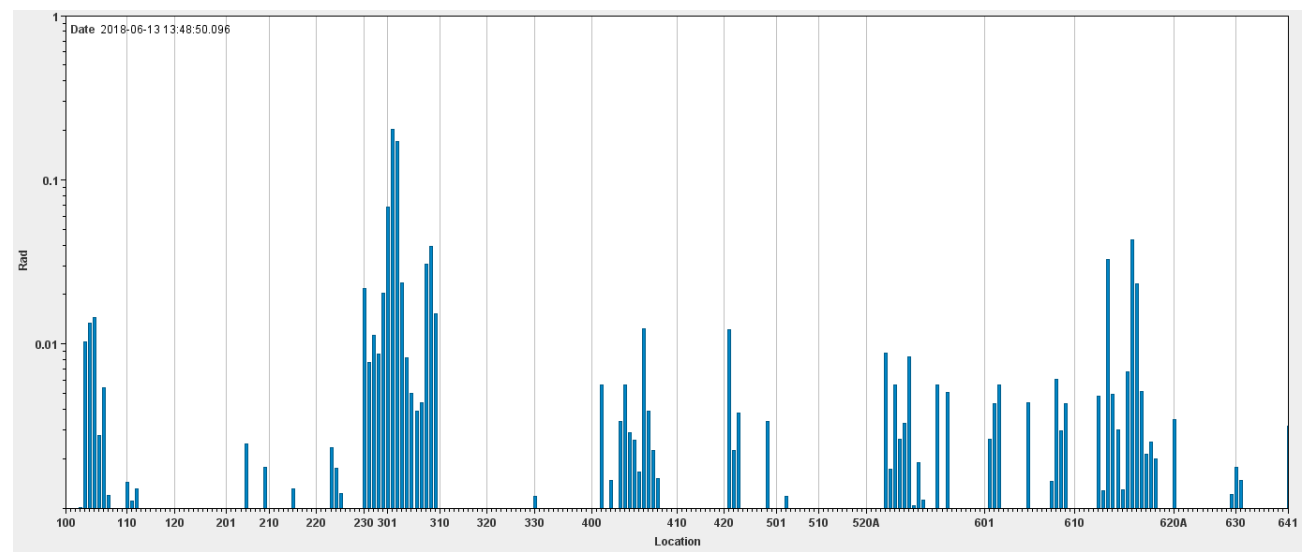




\section{Summary and Future running}

- Running 700kW consistently since Jan 2017

- Added collimators

- New damper during slip-stacking

- Power limits

- Current limit 54E12 (NuMI target limit). This corresponds to $777 \mathrm{KW}$ with 1.33 sec cycle time.

- MI is limited by the available RF power to $62 \mathrm{E} 12$ which corresponds to $892 \mathrm{KW}$ with $1.33 \mathrm{sec}$

- Future plans

- Recycler Lattice optimisation

- Recycler Resonance compensation

- $1.2 \mathrm{~s}$ ramp for $\mathrm{Ml}$ (10\% increase in power)

- Gamma-t jump for MI 


\section{Back-up}




\section{Effect on RR collimators on losses with damper on}

No Collimation, Damper ON

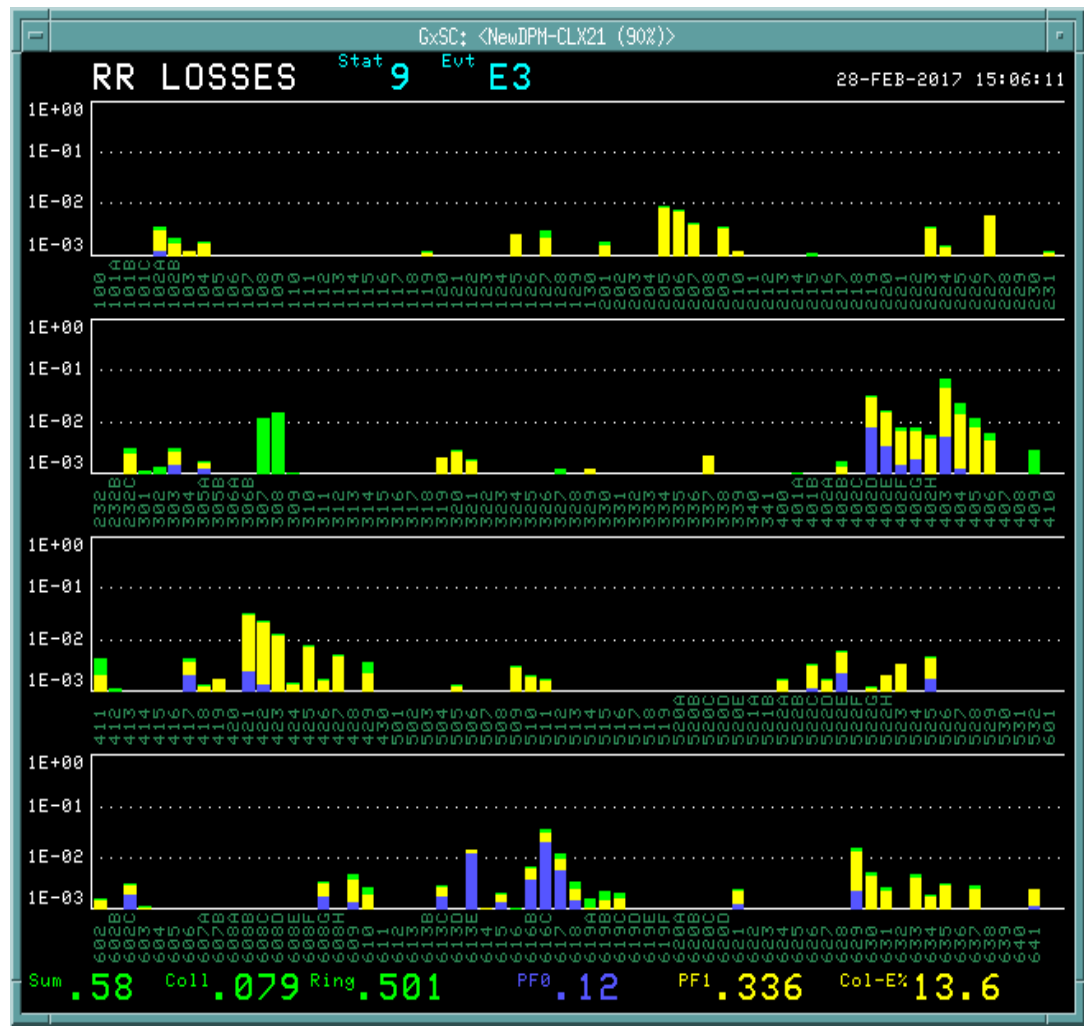

Collimation On, Damper ON

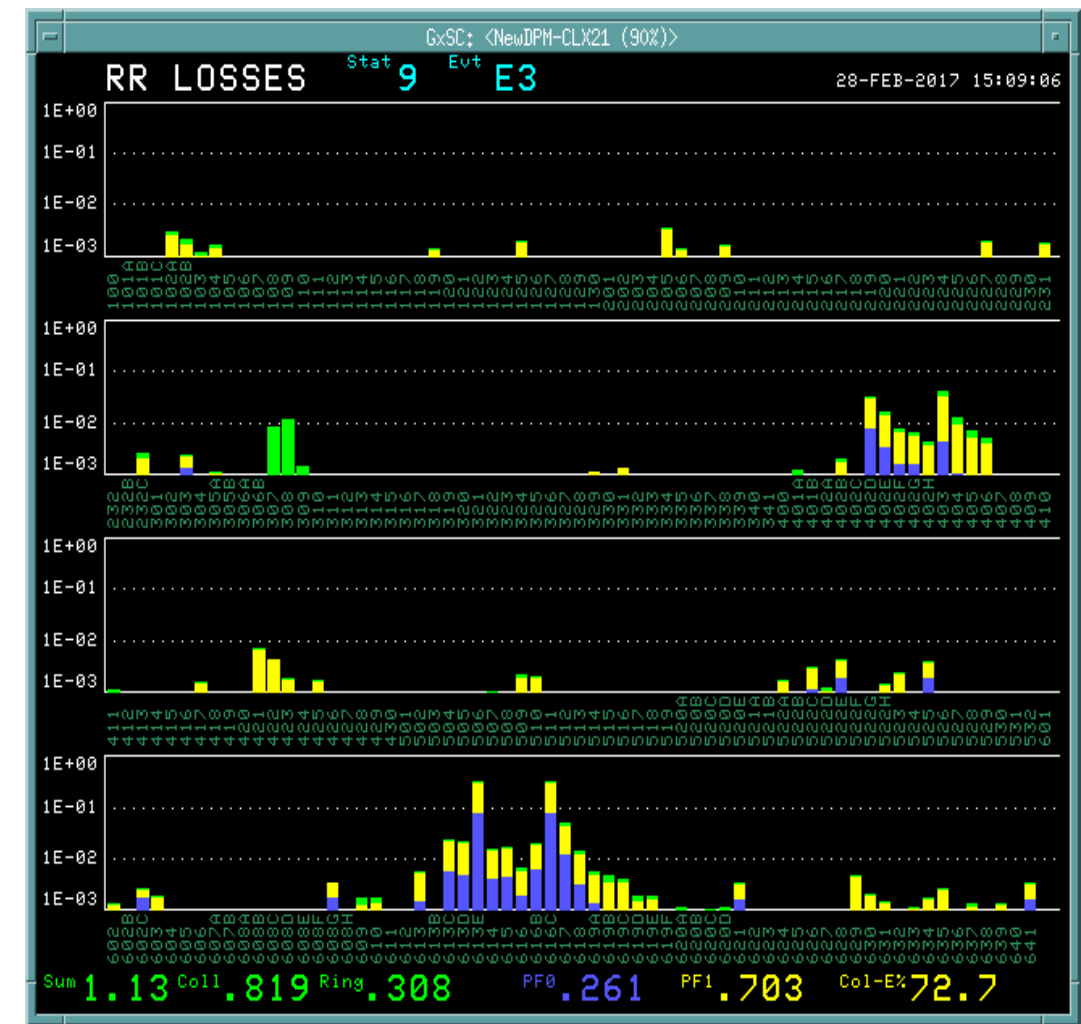

- We need the Recycler collimators even with the new damper! 


\section{Lattice optimisation}
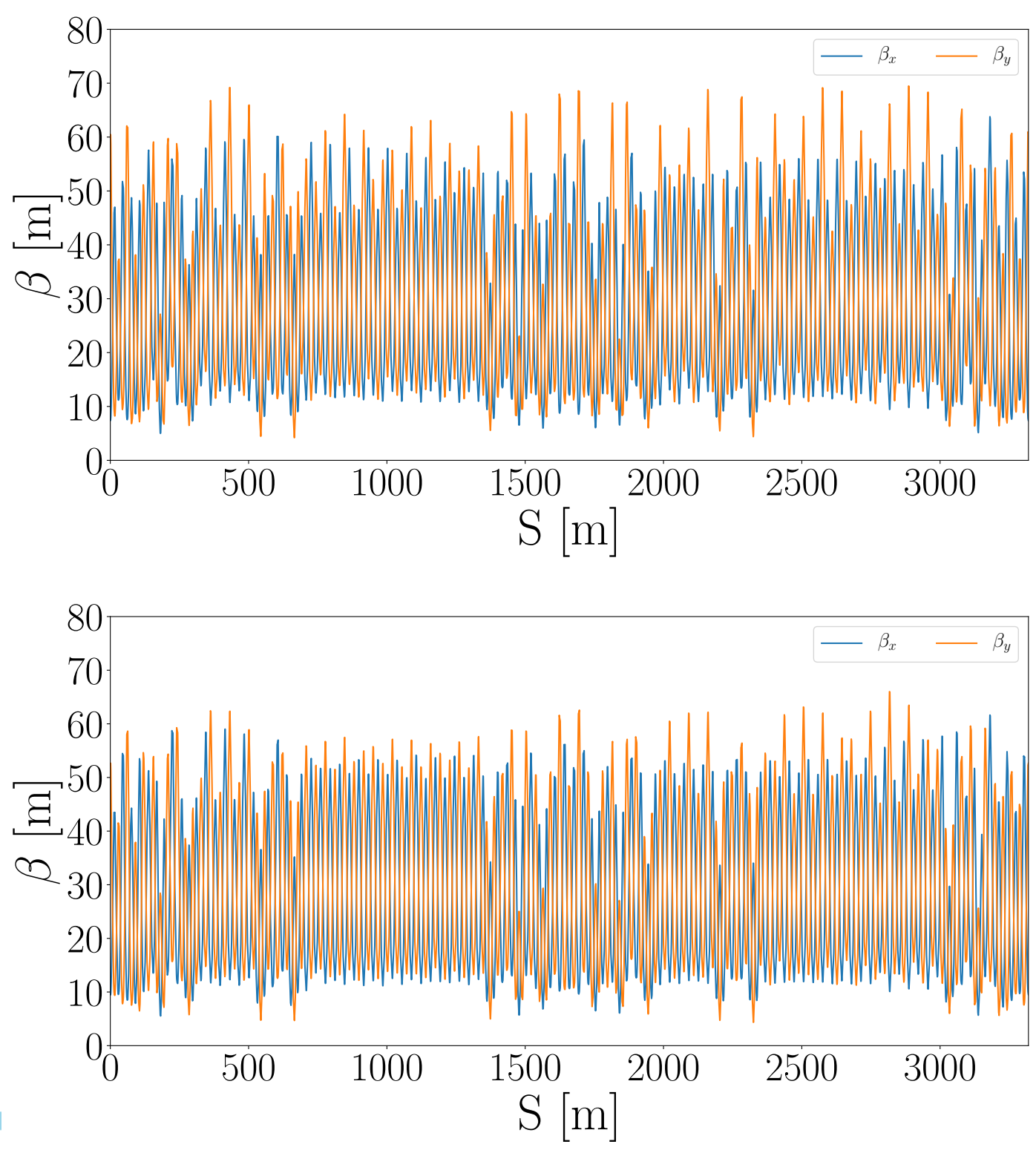


\section{Resonance compensation}
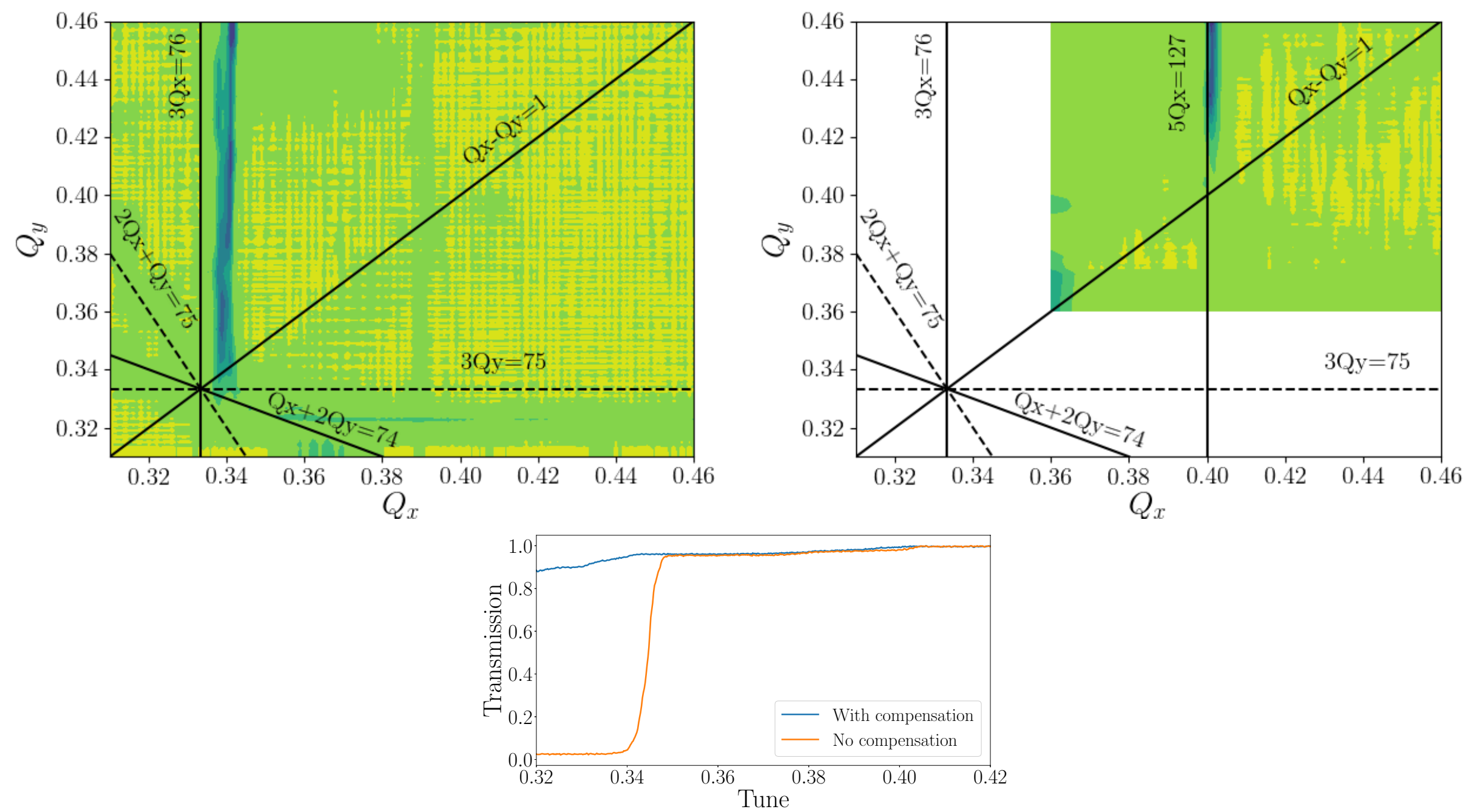

\section{Fermilab}




\section{Gamma t jump}
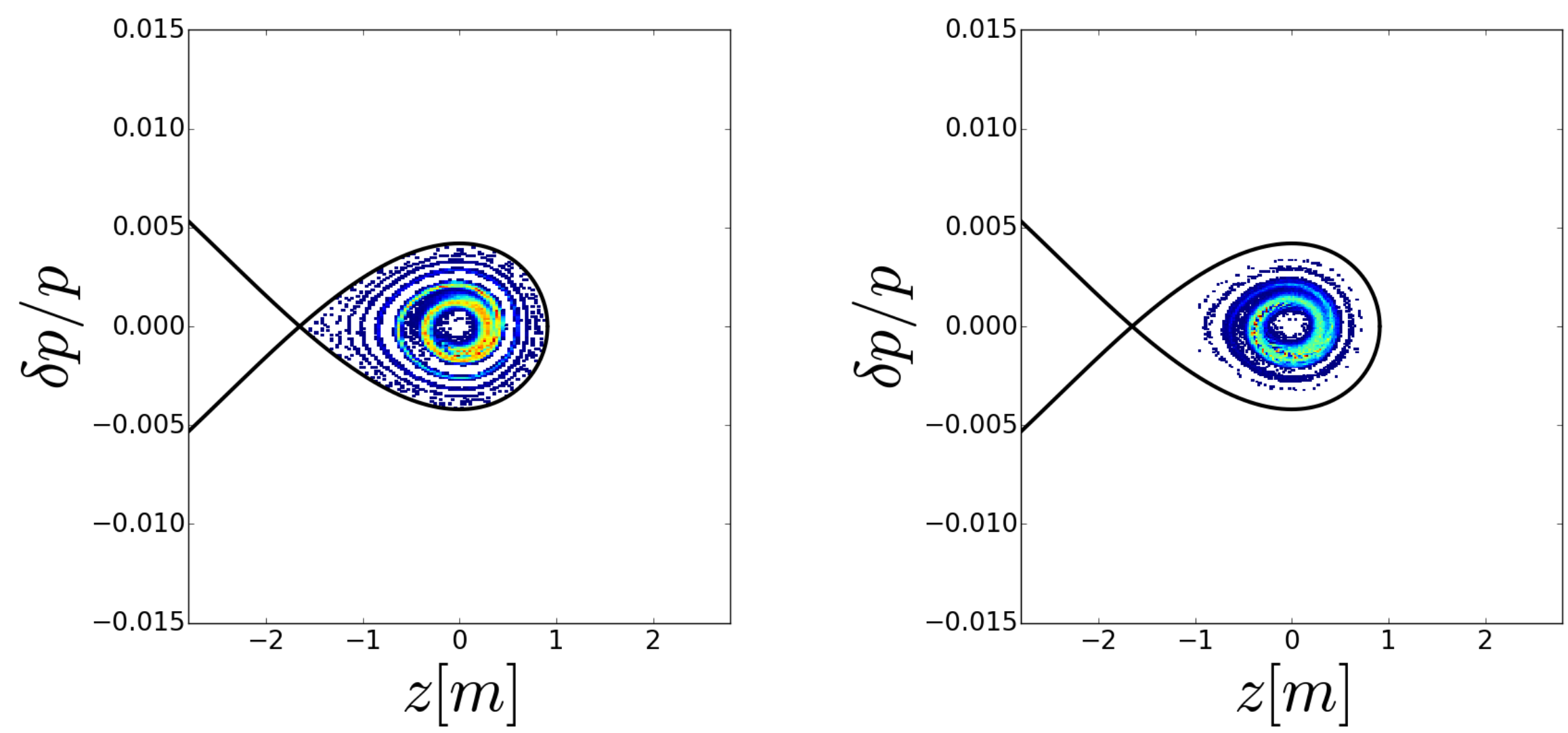